Check for updates

Cite this: RSC Adv., 2018, 8, 41603

Received 6th October 2018

Accepted 26th November 2018

DOI: $10.1039 / c 8 r a 08263 d$

rsc.li/rsc-advances

\section{Monolithic zirconia aerogel from polyacetylacetonatozirconium precursor and ammonia hydroxide gel initiator: formation mechanism, mechanical strength and thermal properties $\dagger$}

\author{
Benxue Liu, DD *a Min Gao, ${ }^{a}$ Xiaochan Liu, ${ }^{a}$ Yongshuai Xie, ${ }^{\text {b }}$ Xibin Yi, ${ }^{\text {*a }}$ Luyi Zhu, ${ }^{b}$ \\ Xinqiang Wang ${ }^{(D)}{ }^{b}$ and Xiaodong Shen ${ }^{a c}$
}

Zirconia $\left(\mathrm{ZrO}_{2}\right)$ aerogels are potential candidates for use at temperatures higher than those attainable with silica aerogels. However, fabricating a robust $\mathrm{ZrO}_{2}$ aerogel with a high thermal stability is still a challenge. The extreme electronegativity of Zr makes the hydrolysis and polycondensation of zirconium precursors difficult to control, leading to poor structural integrity and unsatisfactory physical properties. In the present research, we prepared a $\mathrm{ZrO}_{2}$ aerogel by using a synthetic zirconium precursor, namely polyacetylacetonatozirconium (PAZ), and ammonia hydroxide as the gel initiator. The ammonia hydroxide catalyzes the cross-linking of PAZ via promotion of the dehydration between hydroxyls in PAZ and the acetylacetonate group in PAZ binds the zirconium ion firmly upon the addition of ammonia hydroxide to avoid a gel precipitate. A monolithic $\mathrm{ZrO}_{2}$ aerogel with a large diameter size of $4.4 \mathrm{~cm}$ and high optical transmittance was achieved after drying. The surface area and pore volume of the as-dried $\mathrm{ZrO}_{2}$ aerogel were as high as $630.72 \mathrm{~m}^{2} \mathrm{~g}^{-1}$ and $5.12 \mathrm{~cm}^{3} \mathrm{~g}^{-1}$, respectively. They decreased to $188.62 \mathrm{~m}^{2} \mathrm{~g}^{-1}$ and 0.93 $\mathrm{cm}^{3} \mathrm{~g}^{-1}$ after being heat-treated at $1000{ }^{\circ} \mathrm{C}$ for $2 \mathrm{~h}$. The best mechanical performances of the $\mathrm{ZrO}_{2}$ aerogels showed a compressive strength of $0.21 \pm 0.05 \mathrm{MPa}$ and a modulus of $1.9 \pm 0.3 \mathrm{MPa}$ with a density of $0.161 \pm 0.008 \mathrm{~g} \mathrm{~cm}^{-3}$. Both pore structures and mechanical performances varied according to the ammonia hydroxide gel initiator used. The thermal insulating properties of the $\mathrm{ZrO}_{2}$ aerogel performed better than a silica aerogel blanket with a thermal conductivity of $0.020 \mathrm{~W}\left(\mathrm{~m}^{-1} \mathrm{~K}^{-1}\right)$.

\section{Introduction}

Zirconia $\left(\mathrm{ZrO}_{2}\right)$ aerogels are open-cellular, nanoporous materials that are randomly assembled by $\mathrm{ZrO}_{2}$ nanoparticles which have a typical mass fracture character., ${ }^{1,2}$ They were first prepared in 1976 by Teichner et al. through dissolution of zirconium alkoxide in organic solvent, gelation of the sol and supercritical drying of the gel. ${ }^{3}$ Although forty-two years have passed, $\mathrm{ZrO}_{2}$ aerogels have started to ignite research interest ${ }^{4-7}$ because of the growing demands for an aerogel which can be used at temperatures higher than those attainable with silica aerogels, which sinter and lose the mesopores at temperatures above $1000{ }^{\circ} \mathrm{C}$. Since

${ }^{a}$ Qilu University of Technology (Shandong Academy of Science), Advanced Materials Institute, Shandong Provincial Key Laboratory for Special Silicone-Containing Materials, Jinan 250014, P. R. China. E-mail: liubenxue@gmail.com; yixb@sdas.org ${ }^{b}$ State Key Laboratory of Crystal Materials, Institute of Crystal Materials, Shandong University, Jinan 250100, P. R. China

${ }^{c}$ College of Materials Science and Engineering, Nanjing Tech University, Nanjing 210009, P. R. China

$\dagger$ Electronic supplementary information (ESI) available. See DOI: $10.1039 / \mathrm{c} 8 \mathrm{ra} 08263 \mathrm{~d}$
$\mathrm{ZrO}_{2}$ possesses a high melting point of $2715{ }^{\circ} \mathrm{C}$, low thermal conductivity among metal oxides, and both acid and base active centers, $\mathrm{ZrO}_{2}$ aerogels are promising potential candidates in applications of high temperature thermal insulation, ${ }^{8}$ catalysts, ${ }^{9}$ electrodes in solid oxide fuel cells, ${ }^{10}$ etc. However, fabricating a monolithic $\mathrm{ZrO}_{2}$ aerogel with high strength and high thermal stability is still a challenge until now. The mechanical properties and thermal stability, which play a crucial role concerning commercial usage, are governed by the starting aerogel structure, which in turn is greatly affected by the synthesis reaction. In fact, the partial positive charge of the $\mathrm{Zr}$ atoms $\left(\delta^{+} \approx 0.65\right)$ in alkoxides is much higher than Si atoms $\left(\delta^{+} \approx 0.32\right),{ }^{11}$ which makes the hydrolysis and polycondensation of zirconium alkoxides difficult to control, leading to poor structural integrity and unsatisfactory physical properties.

In early studies, zirconium alkoxides were used as the zirconium precursors. ${ }^{12-14}$ The overfast reaction rate of the sequential hydrolysis and polycondensation was modified by the addition of an acid catalyst. ${ }^{15}$ The as-received aerogel could be transparent but generally cracked. ${ }^{2}$ Consequently, the mechanical strengths were not well studied. Due to the high cost of the metal alkoxide 
and the sensitivity to humidity, zirconium alkoxides were gradually replaced by inorganic zirconium salts, i.e. zirconyl chloride, zirconyl nitrate, and zirconium chloride, especially after the propylene oxide (PO) induced gelation method was developed. ${ }^{15}$ The PO captures protons generated from the solvated zirconium precursor smoothly, leading to a slow increase of $\mathrm{pH}$ value. Hence, the inorganic salt precursors transfer into a stable $\mathrm{ZrO}_{2}$ gel network via hydrolysis and polycondensation. Chervin et al. synthesized a $\mathrm{ZrO}_{2}$ aerogel by using zirconium chlorides as the precursors and PO as the gel initiator. ${ }^{16} \mathrm{~A}$ monolithic $\mathrm{ZrO}_{2}$ aerogel with a high surface area of $406 \mathrm{~m}^{2} \mathrm{~g}^{-1}$ was obtained, however, the surface area degraded into $159 \mathrm{~m}^{2} \mathrm{~g}^{-1}$ and $26 \mathrm{~m}^{2}$ $\mathrm{g}^{-1}$ after calcination at 550 and $1000{ }^{\circ} \mathrm{C}$, respectively, indicating the thermal stability of the aerogel via this method needs to be improved further. In addition, epoxides hold disadvantages such as the fact they are toxic, flammable and explosive and they are listed by the US Environmental Protection Agency as a group B2 possible human carcinogen which makes the epoxide induced gelation method not appropriate for mass production. ${ }^{\mathbf{1 7}}$ More recently, strategies for post casting $\mathrm{SiO}_{2}$ thin layers on the initial $\mathrm{ZrO}_{2}$ aerogel have been widely accepted as an efficient way to improve thermal stability as well as mechanical strength. ${ }^{18-20}$

Polyacetylacetonatozirconium (PAZ) is an organozirconium oligomer with a formula expression of $\left\{\mathrm{Zr}(\mathrm{OH})_{3} \text { acac }\right\}_{n}$ (the acac represents the acetylacetonate group). ${ }^{21}$ The coordination between the acac and the $\mathrm{Zr}^{4+}$ ion, forming a structural stable hexatomic ring, suppresses the hydrolysis of the $\mathrm{Zr}^{4+}$ ion effectively. The PAZ alcoholic solution is quite stable so it could resist gelation for several days under room temperature even in the presence of excess water. ${ }^{22}$ The sol-gel transition of PAZ is milder than those of zirconium alkoxides and zirconium inorganic salts. This provides a fine control of the microstructure of sol-gel products, and consequently the related physical properties. In a recent communication, ${ }^{23}$ we reported the synthesis and characteristics of a monolithic $\mathrm{ZrO}_{2}$ aerogel by using PAZ as the zirconium precursor and PO as the gel initiator. The asreceived $\mathrm{ZrO}_{2}$ aerogel has better mechanical strength and high temperature thermal stability at $1000{ }^{\circ} \mathrm{C}$ than those synthesized by zirconyl chloride and zirconyl nitrate precursors, indicating the potential usage of PAZ as a novel sol-gel precursor for high performance $\mathrm{ZrO}_{2}$ aerogels.

In the present research, under consideration of the drawbacks of the PO induced gelation method, we tried to synthesize a $\mathrm{ZrO}_{2}$ aerogel by using ammonia hydroxide as the gel initiator. Ammonia hydroxide is a strong base that causes gel precipitates rather than gel monoliths to be obtained when it is reacted with zirconium inorganic salts and/or zirconium alkoxides. However, we found that a rigid, homogeneous monolithic $\mathrm{ZrO}_{2}$ wet gel was achieved by using ammonia hydroxide as the gel initiator and PAZ as the zirconium precursor. Moreover, the surface area and pore volume of the as-dried $\mathrm{ZrO}_{2}$ aerogel were found to be larger than those synthesized by a PO gel initiator. The underlying formation mechanism was explored. The dependence of the microstructure, compressive strength and thermal stability at $1000{ }^{\circ} \mathrm{C}$ of the $\mathrm{ZrO}_{2}$ aerogel on the ammonia hydroxide gel initiator were investigated. Lastly, a piece of the $\mathrm{ZrO}_{2}$ aerogel slice with a diameter of $4.4 \mathrm{~cm}$ and a thickness of
$3 \mathrm{~mm}$ was used to study the thermal insulating properties, which included subjecting the slice to an ethanol flame and recording the time-dependent back side temperature.

\section{Experimental section}

\subsection{Chemicals}

Polyacetylacetonatozirconium (PAZ, self-synthesis, $M_{\mathrm{w}} \sim 2000-$ 3000), tetraethoxysilane (TEOS, Aladdin, 98\%), formamide (FA, Aladdin, 99\%), anhydrous ethanol (EtOH, Fuyu, 99.5\%), ammonia hydroxide $\left(\mathrm{NH}_{3} \cdot \mathrm{H}_{2} \mathrm{O}\right.$, Aladdin, 25-28\%) and distilled water (DI).

\subsection{Synthesis of the $\mathrm{ZrO}_{2}$ aerogel}

For a typical synthesis, $1.3 \mathrm{~g}$ PAZ was added into $15 \mathrm{~mL}$ anhydrous alcohol with magnetic stirring. After total dissolution, a clear yellow solution was obtained. Then, $5 \mathrm{~mL}$ distilled water and $200 \mu \mathrm{L}$ FA were added into the solution in turn. After being magnetically stirred for $30 \mathrm{~min}$, designated amounts of ammonia hydroxide of $100 \mu \mathrm{L}, 200 \mu \mathrm{L}$ and $400 \mu \mathrm{L}$ were added into three PAZ sol samples which were denoted $\mathrm{NH}_{3}-1, \mathrm{NH}_{3}-2$ and $\mathrm{NH}_{3}-3$, respectively. Subsequently, the sols were transferred into polypropylene molds, sealed and placed into a water bath at $70{ }^{\circ} \mathrm{C}$. The sol gradually turned into a monolithic gel. After gelation, the wet gel was demolded, aged under room temperature for 1.5 days and washed with ethanol every $12 \mathrm{~h}$. For the strengthening of the skeleton of the wet gel, the wet gel was aged in a TEOS/EtOH mixed solution with a volume ratio of $1: 1$ for 3 days. Then, the unreacted TEOS/EtOH mixed solution was exchanged by EtOH. At last, the wet gel was dried in an autoclave with supercritical fluid $\mathrm{N}_{2}$-ethanol. The temperature and pressure of the supercritical fluid were set as $270{ }^{\circ} \mathrm{C}$ and $9 \mathrm{MPa}$. The autoclave held the desired temperature and pressure for $2 \mathrm{~h}$ to effectively remove the solvent.

\subsection{Characterization}

IR spectra were recorded on a Nicolet 5DX-FTIR spectrometer using the $\mathrm{KBr}$ pellet method in the range of $4000-375 \mathrm{~cm}^{-1} \cdot \mathrm{N}_{2}$ adsorption-desorption at $77 \mathrm{~K}$ was measured by the JW-BK112 surface area and pore size analyzer after the samples were evacuated at $180{ }^{\circ} \mathrm{C}$ for $5 \mathrm{~h}$ under vacuum. The pore size distribution and the pore volume were determined via the BJH (Barrett-Joyner-Halenda) method from the adsorption curve. The morphologies of the obtained aerogel were determined by SUPRA $^{\mathrm{TM}} 55$ Thermal Field Emission Scanning Electron Microscopy. Transmission electron microscopy (TEM) images were recorded using a JEM-200CX electron microscope operating at $20 \mathrm{kV}$. The density was determined by measuring the weight and volume of the aerogel, respectively. X-ray diffraction (XRD) was performed on a Bruker D8 advance X-ray diffractometer at $40 \mathrm{kV}$ and $100 \mathrm{~mA}$ with $\mathrm{CuK} \alpha(\lambda=1.540598 \AA)$ radiation, employing a scanning rate of $5^{\circ} \mathrm{min}^{-1}$ in the $2 \theta$ range from $10^{\circ}$ to $80^{\circ}$. The compressive strength of the aerogel was measured by using a WDW-5 Electronic Testing Machine under a quasi-static condition at a cross head speed of $1 \mathrm{~mm} \mathrm{~min}^{-1}$. 


\section{Results and discussion}

\subsection{Gelation and appearance}

The reaction between ammonia hydroxide and the zirconium precursors usually achieves a precipitate due to the over-fast reaction rate. Huang et al. prepared a $\mathrm{ZrO}_{2}$ aerogel via the sol-gel synthesis of the $\mathrm{ZrO}_{2}$ wet gel by using zirconium sulfate as the zirconium precursor and ammonia as the gel initiator followed by ethanol SCD. ${ }^{24}$ The produced wet gel was slurry and only $\mathrm{ZrO}_{2}$ aerogel powders rather than a monolith were obtained after drying. However, in our research, the PAZ sol remained clear and unchanged for several days at room temperature after the addition of ammonia hydroxide which is very different from those of the zirconium inorganic salts and zirconium alkoxides counterparts. After being transferred into a $70{ }^{\circ} \mathrm{C}$ water bath, the PAZ sol gradually lost flowability and turned into a rigid, homogeneous wet gel. The gel time is about $1.5 \mathrm{~h}$ for $\mathrm{NH}_{3}-1$. With the increase of ammonia hydroxide, the gel time decreases to about $45 \mathrm{~min}$ and $30 \mathrm{~min}$ for $\mathrm{NH}_{3}-2$ and $\mathrm{NH}_{3}-3$, respectively. The $\mathrm{NH}_{3}-1$ wet gel has a high homogeneity so that a large sized $\mathrm{ZrO}_{2}$ aerogel with high optical transmission was achieved after drying as shown in Fig. 3. It is interesting to explore the underlying formation mechanism of the monolithic gel instead of precipitate during the reaction between the PAZ precursor and ammonia hydroxide gel initiator. The $\mathrm{NH}_{3}-1$ wet gel was ambiently dried in a drying oven at $50{ }^{\circ} \mathrm{C}$. After that, the IR spectrum of the as-received $\mathrm{NH}_{3}-1$ xerogel was measured to be compared to that of PAZ. As shown in Fig. 1a, in PAZ, the absorption peak at $1588 \mathrm{~cm}^{-1}$ is ascribed to the stretching vibration of the carbonyl coming from the coordinated acac group. The absorption peak at $1530 \mathrm{~cm}^{-1}$ comes from the ethylene linkage of the acac group. ${ }^{25}$ These two absorption peaks were both observed in the $\mathrm{NH}_{3}-1$ xerogel indicating the acac group remained in the xerogel as well as the $\mathrm{NH}_{3}-1$ wet gel. The absorption peak at $3446 \mathrm{~cm}^{-1}$ broadens in the $\mathrm{NH}_{3}-1$ wet gel due to the formation of hydrogen bonds between the hydroxyls. The emerged blunt peaks near $500 \mathrm{~cm}^{-1}$ in the $\mathrm{NH}_{3}-1$ xerogel is evidence of the formation of $\mathrm{Zr}-\mathrm{O}-\mathrm{Zr}$ networks. ${ }^{26} \mathrm{We}$ inferred that, with the addition of ammonia hydroxide followed by the increase of the $\mathrm{pH}$ value, dehydration between the hydroxyls in PAZ occurred, leading to blunt peaks near $500 \mathrm{~cm}^{-1}$. With the formation of $\mathrm{Zr}-\mathrm{O}-\mathrm{Zr}$ networks, the interactions of the PAZ precursor oligomer were promoted, boosting the emergence of hydrogen bonds which is a consequence of the broadened peak at $3446 \mathrm{~cm}^{-1}$ in $\mathrm{NH}_{3}-1$. Both the molecular structures (the middle row in Fig. 2) and the reaction equations (the bottom row in Fig. 2) could illustrate that dehydration occurred within the PAZ precursors. As a result, the $\mathrm{Zr}-\mathrm{O}-\mathrm{Zr}$ networks act as cross-linking points inducing the gelation of PAZ as shown in the formation scheme (the top row in Fig. 2). The IR spectra of the as-received $\mathrm{NH}_{3}-1, \mathrm{NH}_{3}-2$, and $\mathrm{NH}_{3}-1$ aerogel were measured and are shown in Fig. 1b. As indicated in the figure, the peaks located at 3431 and $1632 \mathrm{~cm}^{-1}$ belong to the surface absorbed $-\mathrm{OH}$ and $\mathrm{H}_{2} \mathrm{O}$. The peaks located at 2982 and $1396 \mathrm{~cm}^{-1}$ are ascribed to $-\mathrm{CH}_{2}-$ and $\mathrm{CH}_{3}$. Due to silylation treatment as shown in Fig. 2, the peak of $\mathrm{Si}-\mathrm{O}-\mathrm{Si}$ is located at $1066 \mathrm{~cm}^{-1} .^{27}$ The peaks at 794 and $455 \mathrm{~cm}^{-1}$ come from the $\mathrm{Zr}-$ $\mathrm{O}-\mathrm{Zr}$ network which formed during the gelation process as we analyzed. The absorption peaks ascribed to the acac group in the PAZ precursor were not observed since they were removed during SCD, either being dissolved in ethanol or from pyrolysis at high temperatures. After drying, only $\mathrm{ZrO}_{2}$ networks and some surface groups remained (Fig. 2).

After drying, as shown in Fig. 3a, enough $\mathrm{ZrO}_{2}$ aerogels cylinders with diameters of $\sim 1 \mathrm{~cm}$ for the study of the physical properties were obtained, indicating that our method has good reproducibility. The molded $\mathrm{ZrO}_{2}$ aerogel cylinders obtained after SCD had a meniscus (shown in Fig. S1 $\dagger$ ) on the surfaces, making the accurate determination of the physical properties difficult. The meniscus was eliminated by polishing on sand paper, producing a cylinder with a regular shape, indicating the excellent processability. ${ }^{28}$ Fig. 3b shows the photograph of a large sized $\mathrm{NH}_{3}-1$ aerogel monolith with a large diameter size of $4.4 \mathrm{~cm}$. The aerogel has high optical transmittance so that the quadrille paper is distinguished through the aerogel monolith. We synthesized a $\mathrm{ZrO}_{2}$ aerogel by using $\mathrm{PAZ}$ as the zirconium precursors and $\mathrm{PO}$ as the gel initiator for comparison. The aerogel gelled by PO has better optical transmittance than that of $\mathrm{NH}_{3}-1$ as shown in Fig. $3 \mathrm{~b}$.
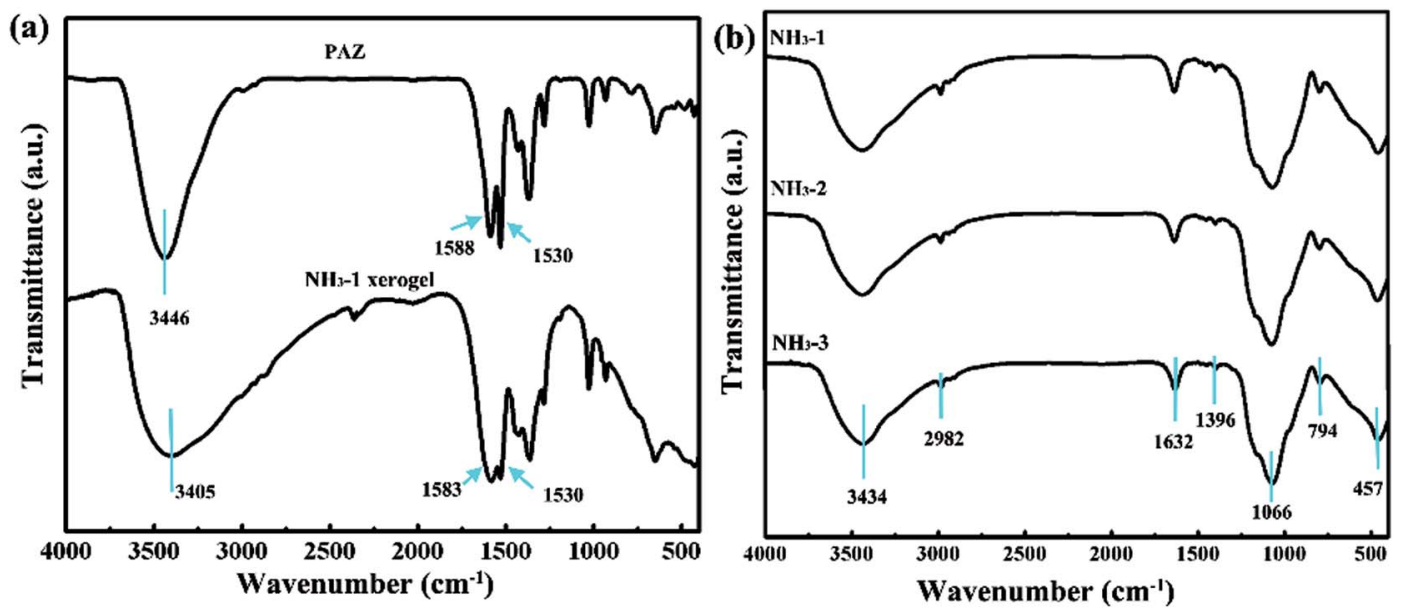

Fig. 1 (a) IR spectra of PAZ and the $\mathrm{NH}_{3}-1$ xerogel. (b) IR spectra of the $\mathrm{NH}_{3}-1, \mathrm{NH}_{3}-2$, and $\mathrm{NH}_{3}-3$ aerogels. 


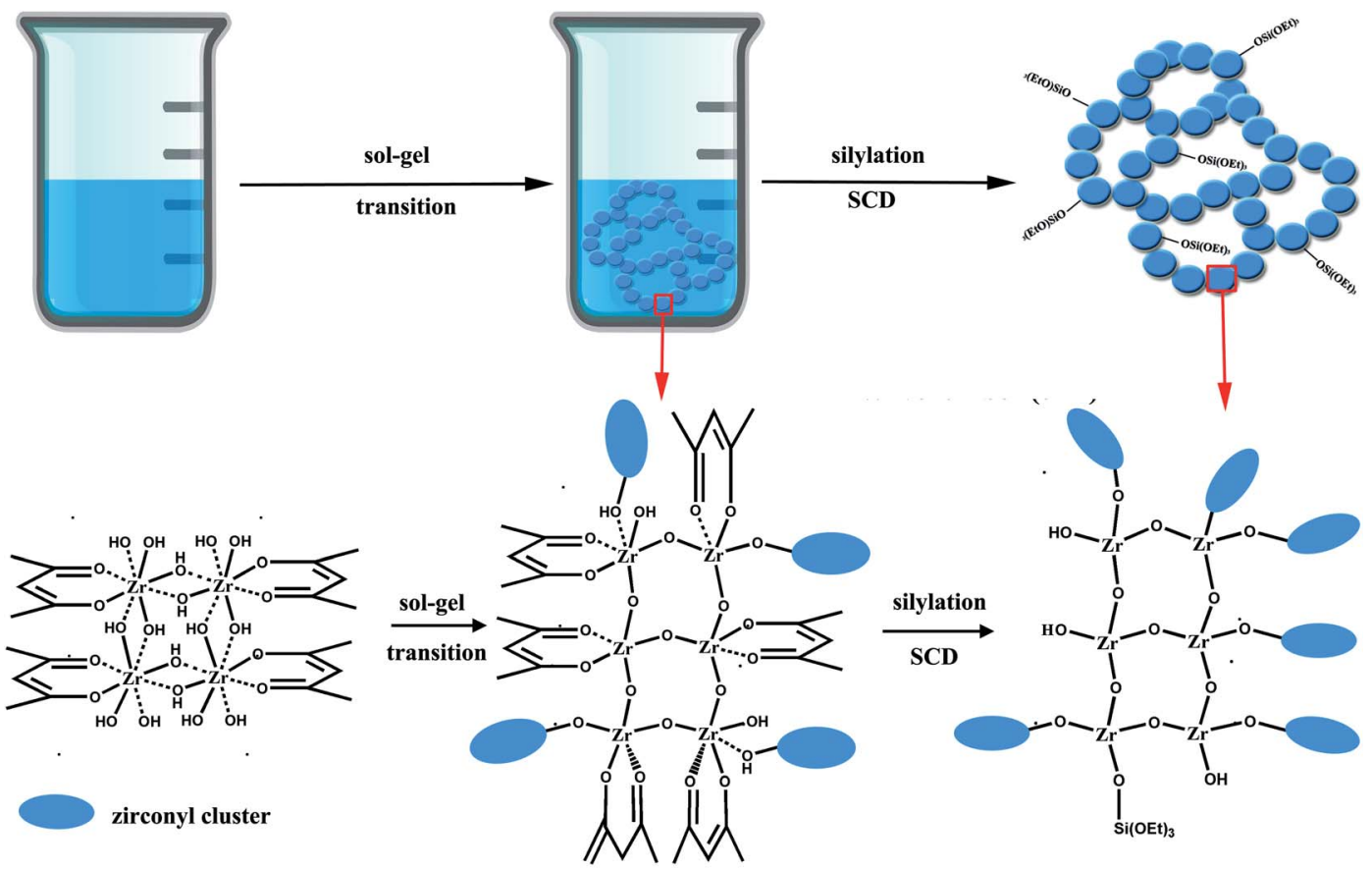

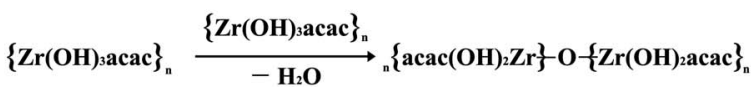

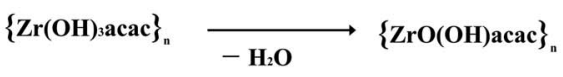

$$
\begin{aligned}
& \left.{ }_{n}\{\operatorname{acacOZr}\} \text { OH } \underset{- \text { EtOH }}{\stackrel{\mathrm{Si}(\mathrm{OEt})_{4}}{\longrightarrow}}{ }_{n}\{\operatorname{acacOZr}\} \text { O-Si(OEt) }\right)_{3}
\end{aligned}
$$

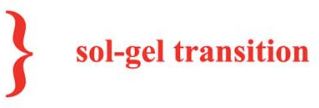

silylation

Fig. 2 Schematic of the formation mechanism of the $\mathrm{ZrO}_{2}$ aerogel.

We considered that the optical transmittance of the $\mathrm{ZrO}_{2}$ aerogel synthesized by the present method could be further improved via careful control of the gelation rate, ${ }^{29}$ such as further decreasing the ammonia hydroxide amount, lowering the gel temperature, etc. Fig. $3 c$ and $d$ show the typical bluish color in the reflection mode and yellowish-orange color in the transmission mode of the $\mathrm{ZrO}_{2}$ aerogel monolith induced by Rayleigh scattering, indicating the homogeneous microstructure and high optical transmittance of the aerogel. ${ }^{30}$

\subsection{Microstructures}

$\mathrm{N}_{2}$ adsorption/desorption was used to characterize the pore structure of the $\mathrm{ZrO}_{2}$ aerogels and the results are shown in Fig. 4. All isotherm curves are type IV. The flat stages of relative pressure between 0 to 0.8 are attributed to the multilayer adsorption on the external surface of the pores. At the relative pressure of $0.8-1.0$, the abrupt increase of adsorption and the following desorption hysteresis ring result from the capillary condensation of $\mathrm{N}_{2}$ molecules in the mesopores with diameters of $2 \mathrm{~nm}$ to $50 \mathrm{~nm}$. When the relative pressure was closed to 1 , the adsorption was still unsaturated, indicating macropores with diameters larger than $50 \mathrm{~nm}$. The pore size distribution (PSD) was analyzed from the desorption isotherm branch via the $\mathrm{BJH}$ method. As shown in the inset, all $\mathrm{ZrO}_{2}$ aerogels exhibit a mesoporous structure. The peak values of the PSD are located near $20 \mathrm{~nm}$. It is obvious that the PSD curves broaden with the increase of ammonia hydroxide. This is because the increased gel initiator speeds the gelation reaction up, decreasing the homogeneity of the porous structure. According to the $\mathrm{N}_{2}$ adsorption/desorption results, the specific surface area (SSA) and pore volume (PV) were calculated by the BET and BJH method. As shown in Table $1, \mathrm{NH}_{3}-2$ has the largest SSA and PV which reach up to as high as $630.72 \mathrm{~m}^{2} \mathrm{~g}^{-1}$ and $5.12 \mathrm{~cm}^{3} \mathrm{~g}^{-1}$, respectively. The SSA and PV of the $\mathrm{ZrO}_{2}$ aerogel are larger than those of most previously reported research and are only lower than the $\mathrm{ZrO}_{2}$ aerogel synthesized by zirconium alkoxide as the precursor and $\mathrm{PO}$ as the gel initiator. ${ }^{31}$

SEM images of the $\mathrm{ZrO}_{2}$ aerogels are shown in Fig. 5. As Fig. 5a shows, $\mathrm{NH}_{3}-1$ has a typical aerogel porous structure. The inter-connected secondary particles assemble into a threedimensional nanoporous structure with most of the pore diameter sizes located at the mesopores scales. As can be seen from Fig. $5 \mathrm{~b}$ and c, the porous $\mathrm{ZrO}_{2}$ aerogels gradually turn into 

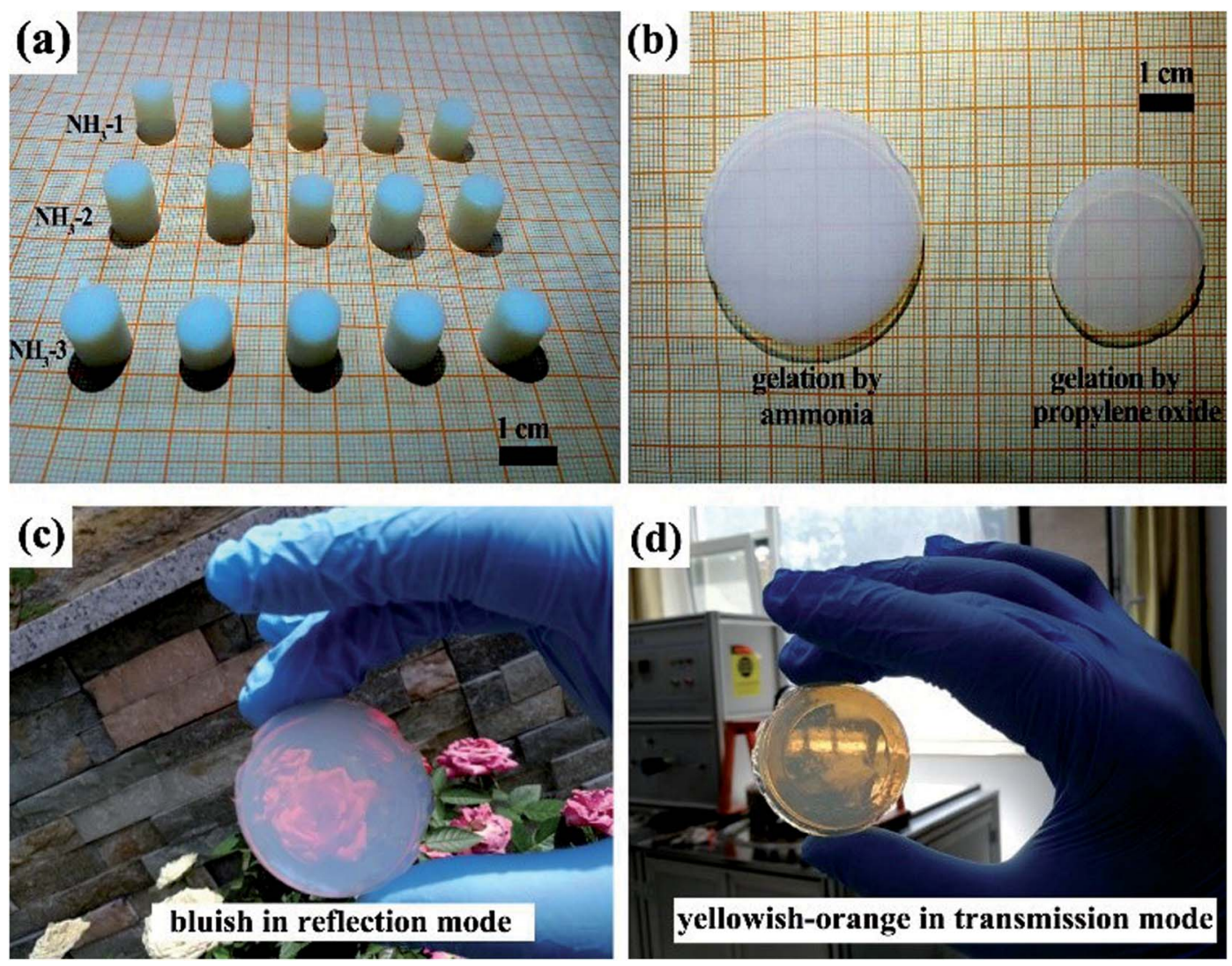

Fig. 3 (a) Photographs of the $\mathrm{NH}_{3}-1, \mathrm{NH}_{3}-2$, and $\mathrm{NH}_{3}-3$ aerogel cylinders with a diameter of $\sim 1 \mathrm{~cm}$. (b) Photograph comparison of the $\mathrm{ZrO} 2$ aerogel gelled by ammonia hydroxide and propylene oxide. Photograph of the bluish appearance in the reflection mode (c) and the yellowishorange appearance in the transmission mode (d) of the $\mathrm{NH}_{3}-1 \mathrm{ZrO}_{2}$ aerogel monolith.

dense structures with the increase of the ammonia hydroxide gel initiator. Large cracks were detected on $\mathrm{NH}_{3}-3$ as shown in Fig. $5 \mathrm{c}$ which was due to the fast gelation rate, leading to

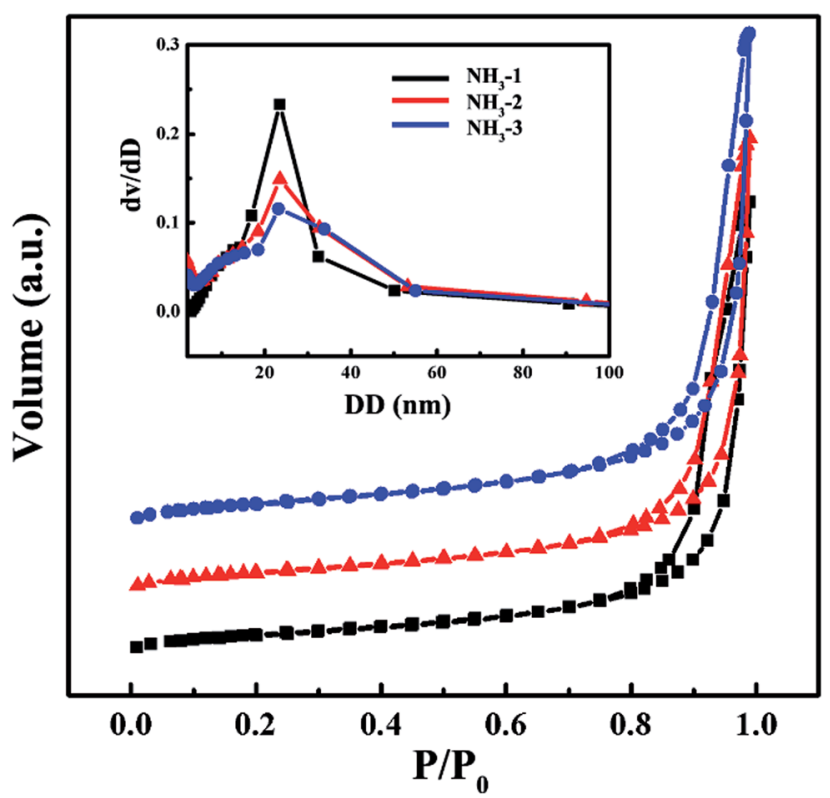

Fig. $4 \mathrm{~N}_{2}$ isotherms of the $\mathrm{NH}_{3}-1, \mathrm{NH}_{3}-2$, and $\mathrm{NH}_{3}-3$ aerogels, the inset is the diameter distribution curves. interior stress and the emergence of cracks. It is consistent with the facts that the gel time decreases with the increase of the ammonia hydroxide gel initiator. We also found in the experiments that the optical transmittance decreased with the increase of the ammonia hydroxide gel initiator which is caused by inhomogeneities such as cracks. TEM was used to further understand the microstructure of these $\mathrm{ZrO}_{2}$ aerogels. As shown in Fig. $5 \mathrm{~d}-\mathrm{f}$, all aerogels exhibit a porous structure. The particles compactly connect to each other, forming the aerogel skeleton. From Fig. 5d-f, it could be observed that the aerogel skeleton became dense with the increase of the ammonia hydroxide gel initiator which is consistent with the SEM results.

\subsection{Mechanical strength}

The mechanical properties of the $\mathrm{ZrO}_{2}$ aerogels were determined via a uniaxial compression test. Before the test, the densities of the $\mathrm{ZrO}_{2}$ aerogel cylinders were calculated from the measured weight divided by the volume of the cylinders. Five

Table 1 The SSA and PV of the as-received $\mathrm{ZrO}_{2}$ aerogel after SCD

\begin{tabular}{lll}
\hline & $\mathrm{SSA}\left(\mathrm{m}^{2} \mathrm{~g}^{-1}\right)$ & $\mathrm{PV}\left(\mathrm{cm}^{3} \mathrm{~g}^{-1}\right)$ \\
\hline $\mathrm{NH}_{3}-1$ & 576.37 & 4.78 \\
$\mathrm{NH}_{3}-2$ & 630.72 & 5.12 \\
$\mathrm{NH}_{3}-3$ & 589.10 & 4.78
\end{tabular}



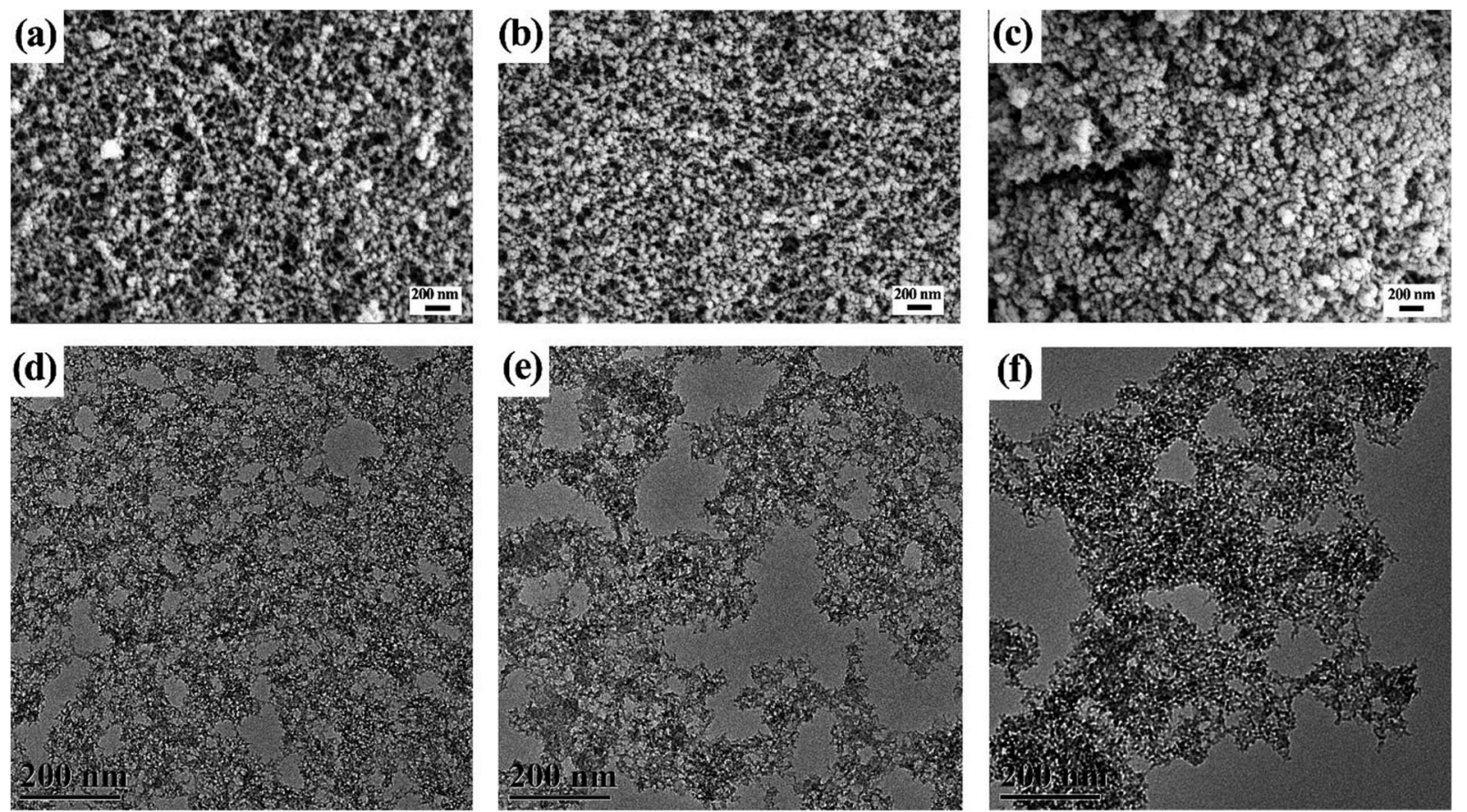

Fig. 5 SEM images of the (a) $\mathrm{NH}_{3}-1$, (b) $\mathrm{NH}_{3}-2$, and (c) $\mathrm{NH}_{3}-3$ aerogels. TEM images of the (d) $\mathrm{NH}_{3}-1$, (e) $\mathrm{NH}_{3}-2$, and (f) $\mathrm{NH}_{3}-3$ aerogels.

cylinders were tested for one $\mathrm{ZrO}_{2}$ aerogel sample. The results are shown in Fig. 6. As shown in the figure, the compressive strength (Young's modulus) of $\mathrm{NH}_{3}-2$ is $0.21 \pm 0.05 \mathrm{MPa}(1.9 \pm$ $0.3 \mathrm{MPa}$ ), slightly larger than that of $\mathrm{NH}_{3}-1$ which is $0.20 \pm$ $0.04 \mathrm{MPa}(1.8 \pm 0.2 \mathrm{MPa})$. The slight increase in the strength of $\mathrm{NH}_{3}-2$ as compared to that of $\mathrm{NH}_{3}-1$ is likely to be caused by measuring errors since the increase is inconspicuous. However, as shown in the above-mentioned SEM results, the interconnections between the secondary particles are improved for $\mathrm{NH}_{3}-2$ with the reduced large sized pores as compared to that of $\mathrm{NH}_{3}-1$, which theoretically allows the aerogels skeleton of $\mathrm{NH}_{3}-2$ to sustain higher loads. ${ }^{32}$ For $\mathrm{NH}_{3}-3$, the compressive stress $(1.8$ $\pm 0.2 \mathrm{MPa}$ ) is unambiguously lower than both $\mathrm{NH}_{3}-2$ and $\mathrm{NH}_{3}-1$. The modulus of $\mathrm{NH}_{3}-3$ is also the lowest among the three aerogels, indicating its poor mechanical properties. But, from the SEM results, the connections between the secondary particles continue to improve for $\mathrm{NH}_{3}-3$. We suggested that the macroscopic cracks in $\mathrm{NH}_{3}-3$ shown in the SEM images lead to the

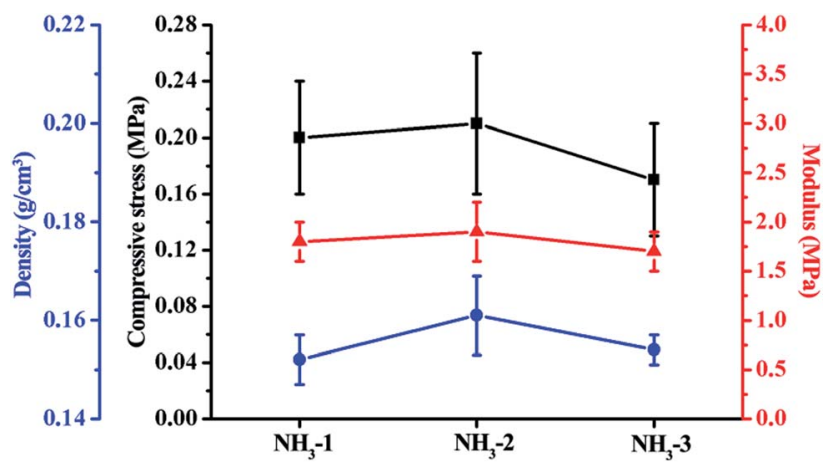

Fig. 6 Densities, compressive stresses and modulus of the $\mathrm{ZrO}_{2}$ aerogels. poor mechanical properties. In the compression test, we found that the $\mathrm{ZrO}_{2}$ aerogels showed a typical brittle nature. The stress-strain curves, shown in Fig. S2, $\dagger$ exhibit sudden decreases in stress when they reach critical values which are identified as fracture points. Herein, the mechanical properties could be explained by a fracture mechanism that shows that the material failure is induced by crack growth. ${ }^{33}$ At the fracture point, a bursting apart of the brittle $\mathrm{ZrO}_{2}$ aerogel was observed during the compression test, shown in Movie S1, $\dagger$ confirming that the failure of the aerogel is induced by the crack growth. As we observed in the SEM images, before the compression test, the intrinsic cracks had penetrated through the $\mathrm{NH}_{3}-3$ body. They are more likely to grow into catastrophic avulsion under external loads, inducing the fracture of the aerogel. As a result, $\mathrm{NH}_{3}-3$ has the lowest compressive stress.

\subsection{Thermal stability upon $1000{ }^{\circ} \mathrm{C}$}

In order to investigate the thermal stabilities of the pores in the $\mathrm{ZrO}_{2}$ aerogels in a high temperature environment, the aerogels were heat-treated in a furnace with a temperature program shown in Fig. 7a. After that, the $\mathrm{N}_{2}$ adsorption/desorption behaviors of the $\mathrm{ZrO}_{2}$ aerogels were studied. As shown in Fig. $7 \mathrm{~b}$, even when the aerogels were calcined at $1000^{\circ} \mathrm{C}$ for $2 \mathrm{~h}$, the isotherm curves still exhibited mesoporous characters as the obvious desorption hysteresis ring was detected during the relative pressure of $0.8-1.0$. When the relative pressure was close to 1 , the adsorption saturation platforms were not obvious in all isotherm curves, indicating the macropores in the aerogel samples. As shown in the inset, $\mathrm{ZrO}_{2}$ aerogels presented mesoporous PSD. The peak value of PSD for the $\mathrm{NH}_{3}-1$ aerogel is still located near $20 \mathrm{~nm}$. However, those of the $\mathrm{NH}_{3}-2$ and $\mathrm{NH}_{3}-3$ aerogels shifted towards a large pore size of $\sim 30 \mathrm{~nm}$. The SSA 
(a)

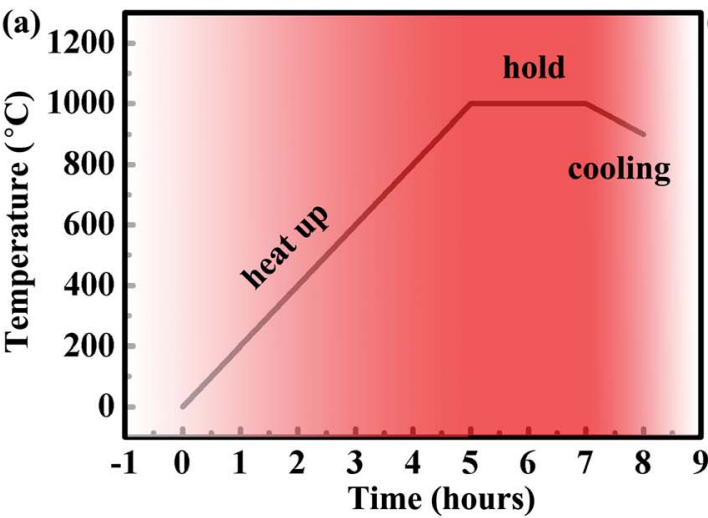

(b)

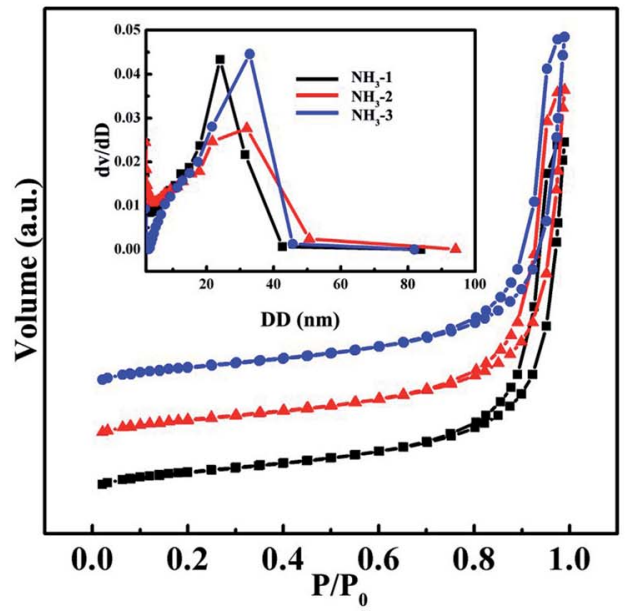

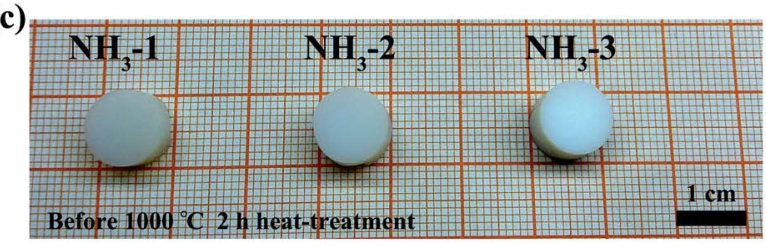

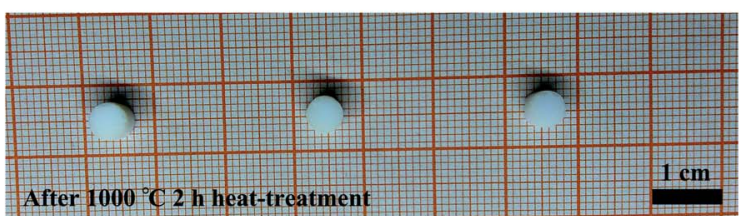

(d)

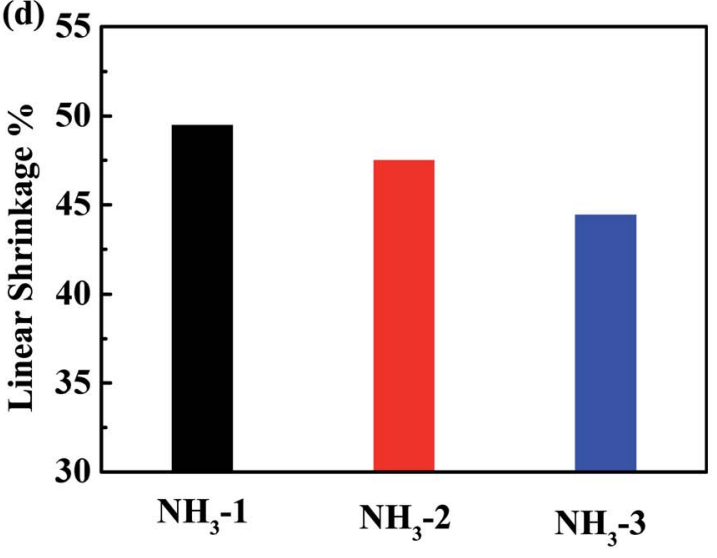

Fig. 7 (a) Heat-treatment temperature programming curve. (b) $\mathrm{N}_{2}$ isotherms of the $\mathrm{NH}_{3}-1, \mathrm{NH}_{3}-2$, and $\mathrm{NH}_{3}-3$ aerogels after being heat-treated at $1000{ }^{\circ} \mathrm{C}$ for $2 \mathrm{~h}$, the inset is the corresponding diameter distribution. (c) Photographs and (d) linear shrinkages of the $\mathrm{ZrO}_{2}$ aerogel cylinders before and after heat-treatment.

and $\mathrm{PV}$ for the $\mathrm{ZrO}_{2}$ aerogels after being heat-treated at $1000{ }^{\circ} \mathrm{C}$ for $2 \mathrm{~h}$ are listed in Table 2 . The $\mathrm{NH}_{3}-2$ has the largest SSA and $\mathrm{PV}$ of $188.62 \mathrm{~m}^{2} \mathrm{~g}^{-1}$ and $0.93 \mathrm{~cm}^{3} \mathrm{~g}^{-1}$, respectively, indicating the best pore thermal stability against high temperatures. The appearances of the aerogel cylinder before and after heattreatment at $1000{ }^{\circ} \mathrm{C}$ for $2 \mathrm{~h}$ were recorded by an optical camera. As shown in Fig. 7c, all cylinders were intact but obviously shrunken. The accurate linear shrinkages (Fig. 7d) were calculated via carefully measuring the diameter changes of the aerogel cylinders before and after heat-treatment. Although the shrinkages of the three aerogel cylinders are almost the same direction as deduced from the photograph shown in Fig. 7c, the calculated linear shrinkage values were $49.50 \%, 47.52 \%$ and $44.44 \%$ for $\mathrm{NH}_{3}-1, \mathrm{NH}_{3}-2$ and $\mathrm{NH}_{3}-3$, respectively, indeed showing a decreased trend for the aerogels with an increased gel initiator of ammonia hydroxide. The weight losses of the three

Table 2 SSA and PV of the $\mathrm{ZrO}_{2}$ aerogel after being heat treated at $1000{ }^{\circ} \mathrm{C}$ for $2 \mathrm{~h}$

\begin{tabular}{lll}
\hline & $\mathrm{SSA}\left(\mathrm{m}^{2} \mathrm{~g}^{-1}\right)$ & $\mathrm{PV}\left(\mathrm{cm}^{3} \mathrm{~g}^{-1}\right)$ \\
\hline $\mathrm{NH}_{3}-1$ & 169.82 & 0.78 \\
$\mathrm{NH}_{3}-2$ & 188.62 & 0.93 \\
$\mathrm{NH}_{3}-3$ & 163.93 & 0.91
\end{tabular}

aerogels during heat-treatment under an air atmosphere were investigated by a thermal analyzer (Fig. S3 $\uparrow$ ). The weight losses show a decrease for $\mathrm{NH}_{3}-1, \mathrm{NH}_{3}-2$ and $\mathrm{NH}_{3}-3$, in accordance with the trend of the linear shrinkage, which is one of the factors resulting in the decreased linear shrinkages. Furthermore, from the TG curves, it should be noted that the weight losses below $100{ }^{\circ} \mathrm{C}$, which are ascribed to surface absorbed hydroxyls and water molecules, ${ }^{23}$ show a decrease for $\mathrm{NH}_{3}-1$, $\mathrm{NH}_{3}-2$ and $\mathrm{NH}_{3}-3$, which means the decreased surface absorbed hydroxyls and water molecules. These surface absorbed hydroxyls are manifested to improve the sintering between the nanoparticles within the aerogel, leading to large linear shrinkages. ${ }^{34-36}$ Herein, the increased linear shrinkages of the aerogel cylinders may result from the increased surface hydroxyls and the increased sintering between nanoparticles. In fact, the shrinkage of the aerogel in a high temperature environment is derived from many factors, such as crystallization, crystal phase changes and sintering between the connected particles, etc. It seems that the linear shrinkages of our $\mathrm{ZrO}_{2}$ aerogels are not satisfactory because an aerogel monolith is considered as thermally stable only when it maintains a linear shrinkage lower than $2 \%$ when being subjected to a specific temperature. Further study is needed to determine how to decrease the linear shrinkages of our $\mathrm{ZrO}_{2}$ aerogel. 


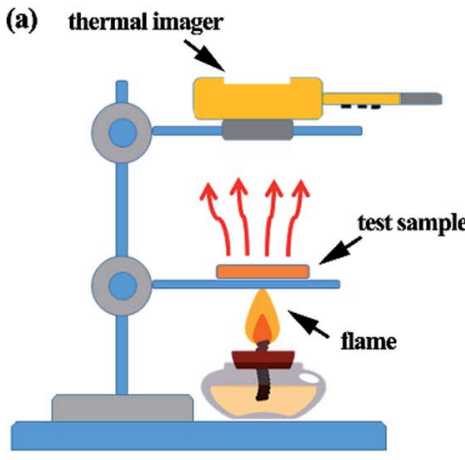

(a)

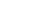

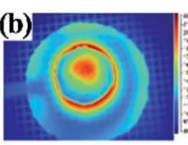
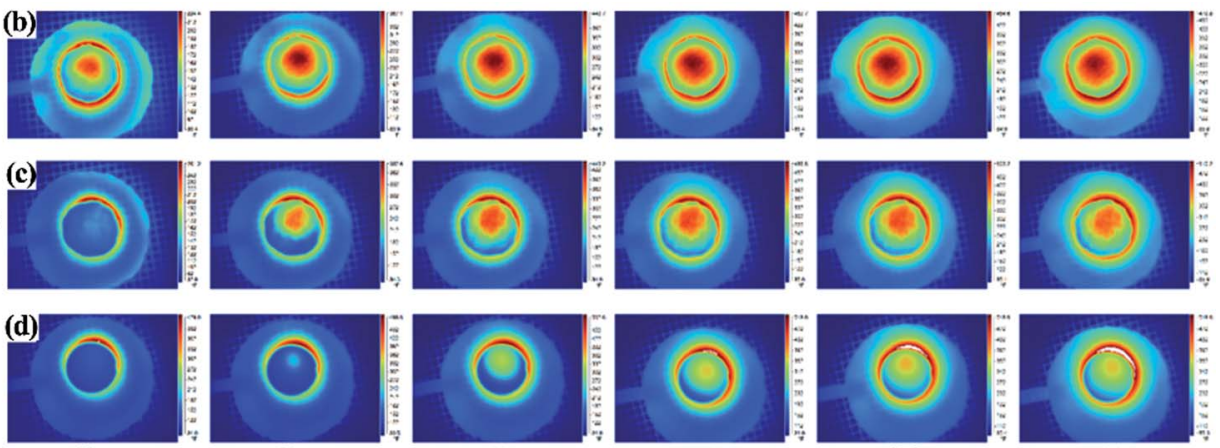

$60 \mathrm{~s}$

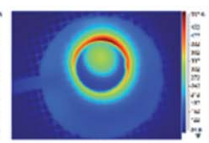

$90 \mathrm{~s}$

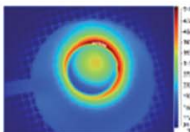

$120 \mathrm{~s}$

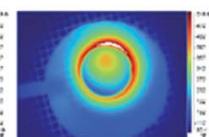

$150 \mathrm{~s}$

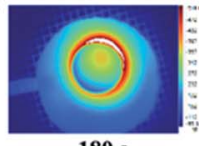

$180 \mathrm{~s}$

8 (a) Schematic of the thermal insulation test. Infrared thermal images of the cold surface of the test samples subjected to an ethanol flame (b) ceramic fiber blanket, (c) silica aerogel blanket, and (d) the $\mathrm{ZrO}_{2}$ aerogel monolith.

\subsection{Thermal insulating properties}

Microstructure studies demonstrate that the as-received $\mathrm{ZrO}_{2}$ aerogels have tremendous nano-pores with diameter sizes similar to the mean free path of air molecules. This makes $\mathrm{ZrO}_{2}$ aerogels capable of restraining the thermal convection of air molecules ${ }^{37}$ efficiently. Because $\mathrm{ZrO}_{2}$ has the lowest skeleton thermal conductivity among metal oxides, $\mathrm{ZrO}_{2}$ aerogels are considered as potential candidates for thermal insulating materials applied in high temperature environments. Herein, the determination of thermal conductivity of $\mathrm{ZrO}_{2}$ aerogels is academically valuable. In previous work, the thermal conductivity of $\mathrm{ZrO}_{2}$ aerogels was studied by transient thermal measurements such as hot wire and hot disk methods. ${ }^{38}$ The steady state thermal measurement of a pure $\mathrm{ZrO}_{2}$ aerogel has been rarely reported due to the need for a large sample size over $10 \mathrm{~cm}$. In our research, in order to study the thermal insulating ability, the $\mathrm{NH}_{3}-1$ aerogel sample with a diameter size of $4.4 \mathrm{~cm}$ and a thickness of $3 \mathrm{~mm}$ was subjected to an alcohol lamp and the time-dependent temperature of the thermal image on the back side was recorded. At the same time, a ceramic fiber blanket, from Luyang Energy-Saving Materials Co., Ltd., with a thermal conductivity of $0.152 \mathrm{~W} \mathrm{~m}^{-1} \mathrm{~K}^{-1}$ and silica aerogel blankets, from Guangdong Alison Hi-Tech Co., Ltd., with a thermal conductivity of $0.020 \mathrm{~W} \mathrm{~m}^{-1} \mathrm{~K}^{-1}$ were used as the comparisons. Both the ceramic fiber blanket and the silica aerogel blanket have the same diameter and thickness as the $\mathrm{NH}_{3}-1 \mathrm{ZrO}_{2}$ aerogel. The alcohol lamp generated a flame of $\sim 400{ }^{\circ} \mathrm{C}$. As shown in Fig. 8, subjecting the test samples to an alcohol flame for an extended time results in a slow increase of the back-side temperature. For the ceramic fiber blanket, the high temperature penetrated the sample as soon as the ceramic fiber blanket was subjected to the flame as shown in the infrared thermal images. The back-side temperature reached up to $235{ }^{\circ} \mathrm{C}$ when the time passed $180 \mathrm{~s}$. As can be seen from Fig. $8 \mathrm{c}$, the back-side temperature increase of the silica aerogel blanket is slower than that of the ceramic fiber blanket. It is due to the lower thermal conductivity of the silica aerogel blanket compared to that of the ceramic fiber blanket, meaning a higher thermal insulating ability. As can be seen in Fig. 8d, it is obvious that the back-side temperature of the $\mathrm{ZrO}_{2}$ aerogel is the lowest among the three test samples. The back-side temperature of the
$\mathrm{ZrO}_{2}$ aerogels, when the time passed $180 \mathrm{~s}$, is $196^{\circ} \mathrm{C}$, indicating a better thermal insulating ability than those of the ceramic fiber blanket and the silica aerogel blanket.

\section{Conclusions}

A monolithic $\mathrm{ZrO}_{2}$ aerogel was achieved by using polyacetylacetonatozirconium (PAZ) as the zirconium precursor and ammonia hydroxide as the gel initiator. The ammonia hydroxide gel initiator catalyzes the cross-linking of the PAZ precursor via promotion of the dehydration of hydroxyls intrinsically existing in PAZ and the acetylacetonate in PAZ binds the zirconium ion firmly to avoid over cross-linking which results in a gel precipitate. After drying, the surface area and pore volume of the $\mathrm{ZrO}_{2}$ aerogels were measured to be as high as $630.72 \mathrm{~m}^{2} \mathrm{~g}^{-1}$ and $5.12 \mathrm{~cm}^{3} \mathrm{~g}^{-1}$, respectively. They remained $188.62 \mathrm{~m}^{2} \mathrm{~g}^{-1}$ and $0.93 \mathrm{~cm}^{3} \mathrm{~g}^{-1}$ after being heat treated at $1000{ }^{\circ} \mathrm{C}$ for 2 hours. The best mechanical performances of the $\mathrm{ZrO}_{2}$ aerogels showed a compressive strength of $0.21 \pm$ $0.05 \mathrm{MPa}$ and a modulus of $1.9 \pm 0.3 \mathrm{MPa}$ with a density of 0.161 $\pm 0.008 \mathrm{~g} \mathrm{~cm}^{-3}$. Both pore structures and mechanical performance varied with the ammonia hydroxide gel initiator used. The thermal insulating property of the $\mathrm{ZrO}_{2}$ aerogel performed better than a ceramic fiber blanket with a thermal conductivity of $0.152 \mathrm{~W} \mathrm{~m}^{-1} \mathrm{~K}^{-1}$ and a silica aerogel blanket with a thermal conductivity of $0.020 \mathrm{~W} \mathrm{~m} \mathrm{~m}^{-1} \mathrm{~K}^{-1}$. We believe that the robust, thermally stable $\mathrm{ZrO}_{2}$ aerogel with good thermal insulating properties achieved via the present method is a potential candidate to be used as a high temperature thermal insulator, catalyst and adsorbent at temperatures above $1000{ }^{\circ} \mathrm{C}$.

\section{Conflicts of interest}

There are no conflicts of interest to declare.

\section{Acknowledgements}

National Natural Science Foundations of China (No. 21603125), Shandong Provincial Natural Science Foundation of China (ZR2016EMP04, ZR2017BEM009), Youth Science Funds of 
Shandong Academy of Sciences (2018QN0031) are acknowledged for financial support.

\section{References}

1 L. BenHammouda, I. Mejri, M. Kadri Younes and A. Ghorbel, Aerogels Handbook, Spriner Science and Business Media, 2011, pp. 127-143.

2 A. Lecomte, F. Blanchard, A. Dauger, M. C. Silva and R. Guinebretiere, J. Non-Cryst. Solids, 1998, 225, 120-124.

3 S. J. Teichner, G. A. Nicolaon, M. A. Vicarini and G. E. Gardes, Adv. Colloid Interface Sci., 1976, 5, 245-273.

4 J. He, H. Zhao, X. Li, D. Su and H. Ji, Ceram. Interfaces, 2018, 44, 8742-8748.

5 X. Hou, R. Zhang and D. Fang, Scr. Mater., 2018, 143, 113116.

6 G. Zu, J. Shen, L. Zou, W. Zou, D. Guan, Y. Wu and Y. Zhang, Microporous Mesoporous Mater., 2017, 238, 90-96.

7 X. Wang, C. Li, Z. Shi, M. Zhi and Z. Hong, RSC Adv., 2018, 8, 8011-8020.

8 H. N. R. Jung, V. G. Parale, T. Kim, H. Hee Cho and H. H. Park, Ceram. Interfaces, 2018, 44, 10579-10584.

9 H. Kalies, N. Pinto, G. MarcelPajonk and D. Bianchi, Appl. Catal., A, 2000, 202, 197-205.

10 K. Tadanaga, K. Imai, M. Tatsumisage and T. Minami, J. Electrochem. Soc., 2002, 149, A773-A777.

11 J. Livage, M. Henry and C. Sanchez, Prog. Solid State Chem., 1988, 18, 259-341.

12 Y. W. Zeng, P. Riello, A. Benedetti and G. Fagherazzi, J. NonCryst. Solids, 1995, 185, 78-83.

13 D. Jin Suh and T. J. Park, Chem. Mater., 1996, 8, 509-513.

14 C. Stocker and A. Baiker, J. Non-Cryst. Solids, 1998, 223, 165178.

15 A. E. Gash, T. M. Tillotson, J. H. Satcher Jr, L. W. Hrubesh and R. L. Simpson, J. Non-Cryst. Solids, 2001, 285, 22-28.

16 A. N. Chervin, B. J. Clapsaddle, H. W. Chiu, A. E. Gash and J. H. Satcher, Chem. Mater., 2005, 17, 3345-3351.

17 Z. Zhang, Q. Gao, Y. Liu, C. Zhou and M. Zhi, RSC Adv., 2015, 5, 84280-84283.

18 Q. Wang, X. Li, W. Fen, H. Ji, X. Sun and R. Xiong, J. Porous Mater., 2014, 21, 127-130.
19 G. Zu, J. Shen, W. Wang, L. Zou, Y. Lian, Z. Zhang, B. Liu and F. Zhang, Chem. Mater., 2014, 26, 5761-5772.

20 H. Gao, Z. Zhang, Z. Shi, M. Zhi and Z. Hong, J. Sol-Gel Sci. Technol., 2018, 85, 567-573.

21 H. Y. Liu, X. Q. Hou, X. Q. Wang, Y. L. Wang and D. Xu, J. Am. Ceram. Soc., 2004, 87, 2237-2241.

22 M. Pan, J. R. Liu, M. K. Lv, D. Xu and D. R. Yuan, Thermochim. Acta, 2001, 376, 77-82.

23 B. Liu, X. Liu, X. Zhao, H. Fan, J. Zhang, X. Yi, M. Gao, L. Zhu and X. Wang, Chem. Phys. Lett., 2019, 715, 109-114.

24 Y. Y. Huang, B. Y. Zhao and Y. C. Xie, Appl. Catal., A, 1998, 172, 327-331.

25 K. Yuan, X. Gan, X. Wang, L. Zhu, G. Zhang and D. Xu, J. Therm. Anal. Calorim., 2017, 127, 1889-1895.

26 D. A. Powers and H. B. Gray, Inorg. Chem., 1973, 12, 27212726.

27 J. He, X. Li, D. Su, H. Ji and X. Zhang, J. Mater. Chem. A, 2016, 4, 5632-5638.

28 A. Benad, F. Jurries, B. Vetter, B. Klemmed and R. Hubner, Chem. Mater., 2018, 30, 145-152.

29 N. Husing and U. Schubert, Angew. Chem., Int. Ed., 1998, 37, 23-45.

30 C. Mandal, S. Donthula, R. Soni, M. Bertino, C. SotiriouLeventis and N. Leventis, J. Sol-Gel Sci. Technol., DOI: 10.1007/s10971-018-4801-0.

31 X. Li, Y. Jiao, H. Ji and X. Sun, Integr. Ferroelectr., 2013, 146, 122-126.

32 X. Hou, R. Zhang and B. Wang, Ceram. Interfaces, 2018, 44, 15440-15445.

33 T. Woignier, A. HafidiAlaoui, J. Primera and J. Phalippou, Key Eng. Mater., 2008, 391, 27-44.

34 R. Xiong, X. Li, H. Ji, X. Sun and J. He, J. Sol-Gel Sci. Technol., 2014, 72, 496-501.

35 Z. Hu, J. He, X. Li, H. Ji, D. Su and Y. Qiao, J. Porous Mater., 2017, 24, 657-665.

36 H. Zhang, X. Li, J. He, Z. Hu and H. Yu, Solid State Phenom., 2018, 281, 105-110.

37 Y. L. He and T. Xie, Appl. Therm. Eng., 2015, 81, 28-50.

38 J. He, X. Li, D. Su, H. Ji and X. J. Wang, J. Eur. Ceram. Soc., 2016, 36, 1487-1493. 